\title{
Pediyatrik Morfea (Lokalize Skleroderma) 14 Olguya Ait Epidemiyolojik Klinik ve Laboratuvar Bulguları
}

\section{Pediatric Morphea (Localized Scleroderma)-Epidemiological, Clinical and Laboratory Findings of 14 Cases}

\author{
Belçin İzol, Hayriye Sarıcaoğlu, Emel Bülbül Bașkan, Sevil Ovalı Toka, \\ Saduman Balaban Adım*, Kenan Aydoğan, Șükran Tunalı \\ Uludag Üniversitesi Tıp Fakültesi Deri ve Zührevi Hastalıkları Anabilim Dalı, Bursa, Türkiye \\ *Uludag Üniversitesi Tıp Fakültesi Patoloji Anabilim Dalı, Bursa, Türkiye
}

Özet

Amaç: Morfea (lokalize skleroderma) çocuklarda sistemik sklerozdan daha sık görülen inflamatuvar bir deri hastalığıdır. Özelikle lineer skleroderma bazen önemli fonksiyonel yetersizlik ve kozmetik bozukluklara neden olmaktadır. Ayrıca hastalarda ekstrakutanöz bulgular, ailede romatolojik hastalık öyküsü ve ANA ve RF pozitifliği gibi patolojik laboratuvar bulguları izlenebilir. Pediyatrik hastaların bu açıdan sorgulanması ve ileri tetkiklerin yapılması önem tașımaktadır.

Literatürde ülkemizdeki morfealı çocukların verileriyle ilgili bilgi bulunmamaktadır. Bu çalıșmayla kliniğimize bașvuran olguların epidemiyolojik, klinik ve laboratuvar bulgularının incelenmesi, literatür verileriyle karșılaștırılması ve Türk popülasyonuna ait ileride çok merkezli ulusal çalıșmalarla desteklenebilecek bir modelin olușturulabilmesi amaçlanmıștır.

Gereç ve Yöntem: Çalıșmaya 2000-2010 yılları arasında Uludağ Üniversitesi Tıp Fakültesi Deri ve Zührevi Hastalıkları Anabilim Dalına bașvuran, tanı anında 18 yașın altında olan 3 erkek, 11 kız, toplam 14 pediyatrik morfealı hasta alındı. Hastaların epidemiyolojik, klinik ve laboratuvar verileri retrospektif olarak incelenerek kaydedildi.

Bulgular: On dört hastanın 3'ü erkekti. Ortalama hastalık bașlangıç yașı 9,5 olarak değerlendirildi. Bașvuru anında hastalık süresi ortalama 21 aydı. En sık görülen klinik tip lineer morfeaydı. Iki hastada kontraktür, bir hastada sol ekstremitede kısalık mevcuttu. Dört hastada livedo retikülaris saptandı, 1 hastada Raynaud fenomeni pozitifti. Tetikleyici faktör olarak travma ve güneș yanığı öyküsü vardı. Bir hastada babada Behçet hastalığına rastlandı. Bir hastada RF pozitifti. Beș hastada ANA 1/100 titrede pozitif saptanırken yaygın morfealı bir hastada 1/1000 titrede anlamlı pozitiflik mevcuttu. Antihiston antikor bir olguda, Lyme Ig M ise 2 olguda pozitifti.

Sonuç: Çocukluk çağında morfeanın erken tanı ve tedavisi deformitelere neden olabilmesi nedeniyle önemlidir. Hastalar detaylı bir anamnezle eșlik edebilecek sistemik bulgular açısından sorgulanmalı ve șüphelenildiğinde ekstrakutanöz tutulum araștırılmalıdır. (Türkderm 2011; 45: 132-6)

Anahtar Kelimeler: Morfea, epidemiyoloji, ekstrakutanöz tutulum

\section{Summary}

Background and Design: Morphea is an inflammatory skin disease seen more frequently than systemic sclerosis in pediatric patients. Important functional deficiencies and cosmetic deformities may develop especially due to linear morphea. Patients may have accompanying extracutaneous involvement, family history of rheumatologic diseases and abnormalities in laboratory parameters like positive ANA and RF. It is important to evaluate pediatric patients accordingly and to carry out further examinations.

Data about pediatric morphea in Turkish population could not be found in the literature. We aimed to evaluate epidemiological, clinical and laboratory findings, to compare the data with those in the literature and to propose a model for Turkish pediatric morphea which can be supported by future multicenter national studies.

Materials and Methods: Fourteen pediatric morphea patients, 3 males and 11 females under the ageof 18, followed up at Uludag University, Medical Faculty, Dermatovenereology Department between 2000-2010 were enrolled in the study. Inclusion criterion was age under 18 years at diagnosis. Epidemiological, clinical and laboratory findings were analyzed retrospectively.

Yazışma Adresi/Address for Correspondence: Dr. Belçın Izol, Uludag Üniversitesi Tıp Fakültesi Deri ve Zührevi Hastalıkları Anabilim Dalı, Bursa, Türkiye E-posta: belcinizol@yahoo.com Geliş Tarihi/Received: 06.09.2010 Kabul Tarihi/Accepted: 29.09.2010

Türkderm-Deri Hastalıkları ve Frengi Arșivi Dergisi, Galenos Yayınevi tarafından basılmıștır.

Turkderm-Archives of the Turkish Dermatology and Venerology, published by Galenos Publishing. 
Results: Only 3 patients were males. The mean age at disease onset was 9.5 years. The mean duration of disease was 21 months. Most frequent type was linear morphea. Two patients had contracture, one had shortness in the left lower extremity, and 4 patients had livedo reticularis. Raynaud's phenomenon was positive in one case. Trauma and sunburn were the trigger factors detected. Behcet's disease was reported in the father of one patient.

One case was RF positive. Five patients had positive ANA in titers of $1 / 100$, while a patient with generalised morphea had significantly higher titer (1/1000). Antihistone antibodies were positive in one patient and 2 cases were Lyme IgM positive.

Conclusion: Early diagnosis and therapy are important since childhood morphea can cause cosmetic deformities. Patients should be evaluated for accompanying systemic symptoms and, extracutaneous involvement should be investigated when the disease is suspected. (Turkderm 201 1; 45: 132-6)

Key Words: Morphea, epidemiology, extracutaneous involvement

\section{Giriş}

Morfea (lokalize skleroderma) dermis ve subkutan yağ dokusunun sklerozuna neden olan inflamatuvar bir deri hastalığıdır. Hastaların \%20'sini çocuklar oluşturmaktadır. Çocuklarda sistemik sklerozdan 10 kat daha sık görülür. ${ }^{1}$ Literatürde çocuk morfealı hastaların epidemiyolojik, klinik ve laboratuvar verilerinin incelendiği çok merkezli retrospektif çalışmalar mevcuttur. ${ }^{2,3,4}$ Fakat ülkemizdeki morfealı çocukların verileriyle ilgili bilgiye rastlanamamıştır. Bu çalışmayla, kliniğimize başvuran morfealı pediatrik olguların epidemiyolojik, klinik ve laboratuvar bulgularının incelenmesi, literatür verileriyle karşılaştırılması ve ileride ülkemize ait çok merkezli ulusal çalışmalara bir model oluşturulması amaçlanmıştır.

\section{Gereç ve Yöntem}

Çalışmaya 2000-2010 yılları arasında kliniğimize başvuran 3 erkek, 11 kız, toplam 14 pediatrik morfealı hasta dahil edildi. Tanı anında hastaların 18 yaşından küçük olması çalışmaya alınma kriteri olarak belirlendi. Hastaların epidemiyolojik, klinik ve laboratuvar bulguları retrospektif olarak incelendi ve cinsiyet, başvuru anındaki yaş, hastalığın başlangıç yaşı, hastalık süresi, hastalığın klinik tipi, tutulan anatomik bölge, hastalığa eşlik eden sistemik bulgu ve semptomlar, tetikleyici faktörler, ailede romatolojik hastalık öyküsü değerlendirildi ve laboratuvar bulguları kaydedildi.

\section{Bulgular}

On dört hastanın 3'ü erkek 11'i kızdı. Hastalık başlangıç yaşı 2-17 arasında değişmekteydi (ortalama 9.5 yaş). Başvuru anında hastalık süresi 1-84 ay (ortalama 21 ay) arasındaydı. Yedi hastada lineer morfea, 5 hastada lokalize plak tip morfea, 1 hastada mikst (lineer+plak) morfea ve bir hastada yaygın morfea tespit edildi. Lineer morfealı 7 hastanın birinde alın orta hatta tutulumla karakterize 'en coup de sabre' (ECDS) mevcuttu. En sık tutulum bölgesi üst ekstremitelerdi. Lineer morfealı hastalarda bilateral tutuluma diğer klinik tiplere göre daha sık rastlandı. Eşlik eden ekstrakutanöz bulgu ve semptomların değerlendirilmesinde 2 hastada kontraktür izlendi. Hastalığı 2 yaşında erken başlamış olan bir olguda sol ekstremitede kısalık saptandı. Dört hastada livedo retikülaris izlenirken, 1 hastada Raynaud fenomeni pozitifti. Bunun yanısıra hastalarda nefes darlığı, disfaji, strabismus, ellerde uyuşma, miyalji, artralji, baş ağrısı gibi eşlik eden sistemik semptomlar mevcuttu. Tetikleyici faktör açısından sorgulanan 9 hastanın birinde travma, bir hastada da güneş yanığı öyküsü vardı. Ailede romatolojik hastalık öyküsü sorgulanan 10 hastanın birinde babada Behçet hastaığı mevcuttu. Hastaların epidemiyolojik ve klinik bulguları, hastalığa eşlik eden sistemik bulgu ve semptomlar Tablo-1'de özetlenmiştir.

iki hastada lökositoz ve 1 hastada demir eksikliği anemisi mevcuttu. Akut faz reaktanları ve immünglobulin düzeylerinde patolojik bulguya rastlanmadı. Romatoid faktör (RF) 4 hastada değerlendirilmişti.

Tablo 1. Olguların demografik, klinik özellikleri ve tetikleyici faktörler

\begin{tabular}{|c|c|c|c|c|c|c|c|}
\hline Hasta no & $\begin{array}{c}\text { Cinsiyet } \\
\text { Hasta } \\
\text { yaşı (yıl) }\end{array}$ & $\begin{array}{c}\text { Hastalık } \\
\text { başlangıç } \\
\text { yaşı (yıl) }\end{array}$ & $\begin{array}{l}\text { Hastalık } \\
\text { Süresi } \\
\text { (ay) }\end{array}$ & Klinik tip & Tutulum bölgesi & $\begin{array}{l}\text { Esslik eden bulgu ve } \\
\text { semptomlar }\end{array}$ & Tetikleyici faktör \\
\hline 1 & $K / 6$ & 2 & 48 & lineer (ECDS) & alın & livedo retikülaris & yok \\
\hline 3 & $\mathrm{~K} / 15$ & 14 & 9 & plak & boyun & nefes darlığı, disfaji, livedo retikülaris & $?$ \\
\hline 6 & $E / 17$ & 17 & 4 & lineer & sağ kol & nefes darlığı & yok \\
\hline 7 & $\mathrm{~K} / 17$ & 16 & 12 & plak & sirt & $\begin{array}{l}\text { parmaklarda uyuşma, } \\
\text { miyalji, artralji, baş ağıısı }\end{array}$ & yok \\
\hline 8 & $\mathrm{E} / 8$ & 8 & 4 & lineer+plak(mikst) & sol ayak & kontraktür, nefes darlığı, disfaji & $?$ \\
\hline 12 & $\mathrm{~K} / 13$ & 11 & 24 & plak & sırt,sağ dirsek & yok & travma \\
\hline 13 & $E / 12$ & 12 & 5 & lineer & sağ kol ve aksilla,sağ uyluk & livedo retikülaris & yok \\
\hline 14 & $\mathrm{~K} / 13$ & 11 & 24 & lineer & sağ kol & yok & güneş yanığı \\
\hline
\end{tabular}


Raynaud fenomeni olan bir hastada RF pozitifti. Antinükleer antikor (ANA) değerlendirmesi yapılan 11 hastanın 5 'inde 1/100 titrede pozitiflik saptanırken yaygın morfealı hastada ileri dilüsyonda 1/1000 titrede anlamlı pozitiflik mevcuttu. Mikst morfealı bir olguda antihiston antikor pozitifti. Lyme Ig M değerlendirilen 8 olgudan lineer sklerodermalı 2 olguda pozitiflik saptandı. Değerlendirilen laboratuvar parametreleri ve patolojik bulgular Tablo-2'de özetlenmiştir.

\section{Tartışma}

Morfea pediyatrik dermatoloji kliniğine başvuran hastaların yaklaşık $\% 0,2$ 'sinde görülen nadir bir hastalıktır. Kızlar erkeklere oranla 2-3 kat daha fazla etkilenmektedir. Zulian ve ark' $n ı n^{2} 750$ juvenil morfealı hasta ile yaptığı çok merkezli çalışmada kızların erkeklere oranı 2,4 olarak bulunmuştur. On dört hastalık serimizde de kız predominansı mevcuttu. Zulian ve ark. ${ }^{2}$ çalışmalarında ortalama hastalık başlangıç yaşını 7,3 yıl, tanı anında ortalama hastalık süresini 1,6 yıl olarak tespit etmiştir. Çalışmamızda ortalama hastalık başlangıç yaşı 9,5 yaş, ortalama hastalık süresi 21 aydı. Yakın zamanda yapılan bir sınıflandırmada morfea; plak tip morfea, lineer skleroderma, yaygın morfea, pansklerotik morfea ve mikst morfea olmak üzere beş gruba ayrılmıştır. ${ }^{5}$ Morfeanın klinik tiplerinin dağııımını belirlemek üzere 87 morfealı hasta üzerinde yapılan bir çalışmada hastaların \%67'sinde lineer, \%29'unda lineer olmayan ve \%4'ünde mikst morfea saptanmıştır. ${ }^{6}$ Klinik tipler içerisinde en sık lineer morfea saptanmış, bunu sırasıyla plak, yaygın ve derin morfeanın izlediği görülmüştür., Çalışmamızda da literatür verilerine uygun olarak en sık lineer morfea görüldü; bunu plak, yaygın ve mikst morfea izlemekteydi. Bu bulgular literatürle uyumluydu.

Morfeada hastalık başlangıcına yakın dönemde intramuskuler aşı uygulaması, travma, böcek ısırığı, güneş yanığı, infeksiyon, ilaç kullanımı ve psikolojik stres gibi tetikleyici faktörler tespit edilebilir ${ }^{8}$. Borrelia ile ilişki bildirilmiş, fakat net olarak kanıtlanmamıştır. ${ }^{9}$ Hastaların \%13,3'ünde $(n=100)$ çevresel faktörlerin varlığı tespit edilmiştir. ${ }^{2}$ On dört hastamızın 2 'sinde $(\% 22,2)$ travma ve yanık gibi tetikleyici faktör öyküsü mevcuttu. Morfealı hastalarda romatoid artrit, sistemik skleroz, sistemik lupus eritematozus, akut romatizmal ateş, Raynaud fenomeni, Behçet hastalığı

\section{Tablo 2. Olguların laboratuvar bulguları}

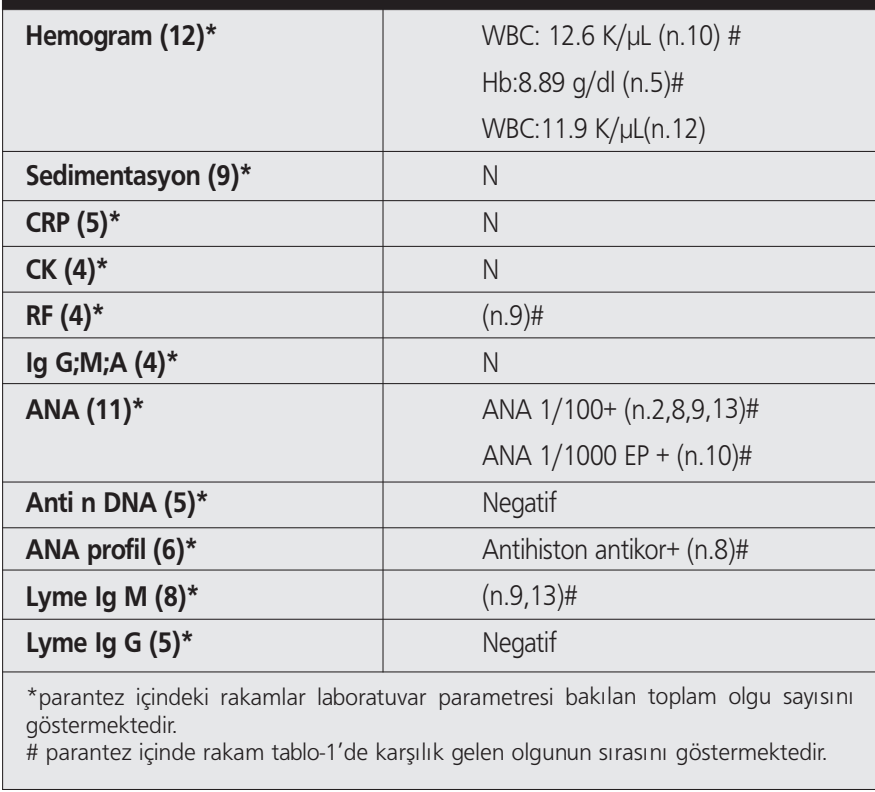

ve diğer immün aracılı hastalıklar açısından 1. ve 2. derece akrabalarda pozitif aile öyküsü bulunabilir. Hastaların \%12'sinde başta romatoid artrit olmak üzere ailede romatolojik hastalık öyküsü bildirilmiştir.2 Çalışmamızda ailede romatolojik hastalık öyküsü sorgulamasında bir hastanın babasında Behçet hastalığı mevcuttu.

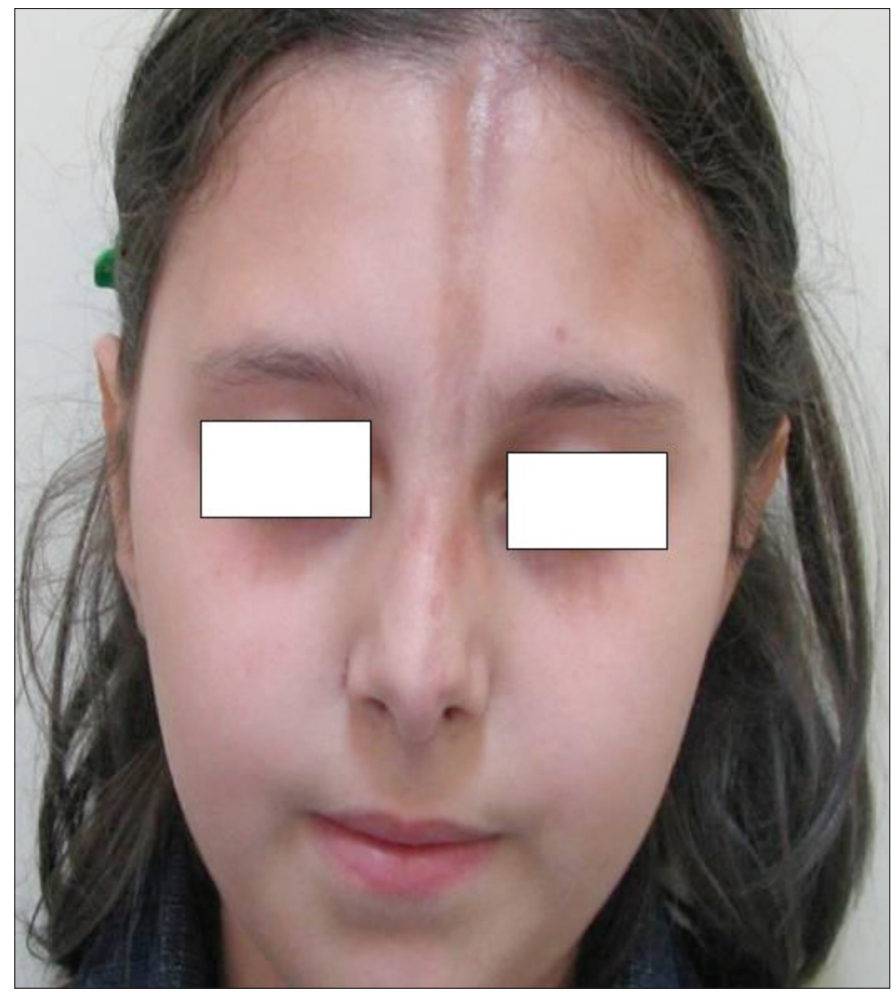

Resim 1. En coup de sabre (Olgu no.1)

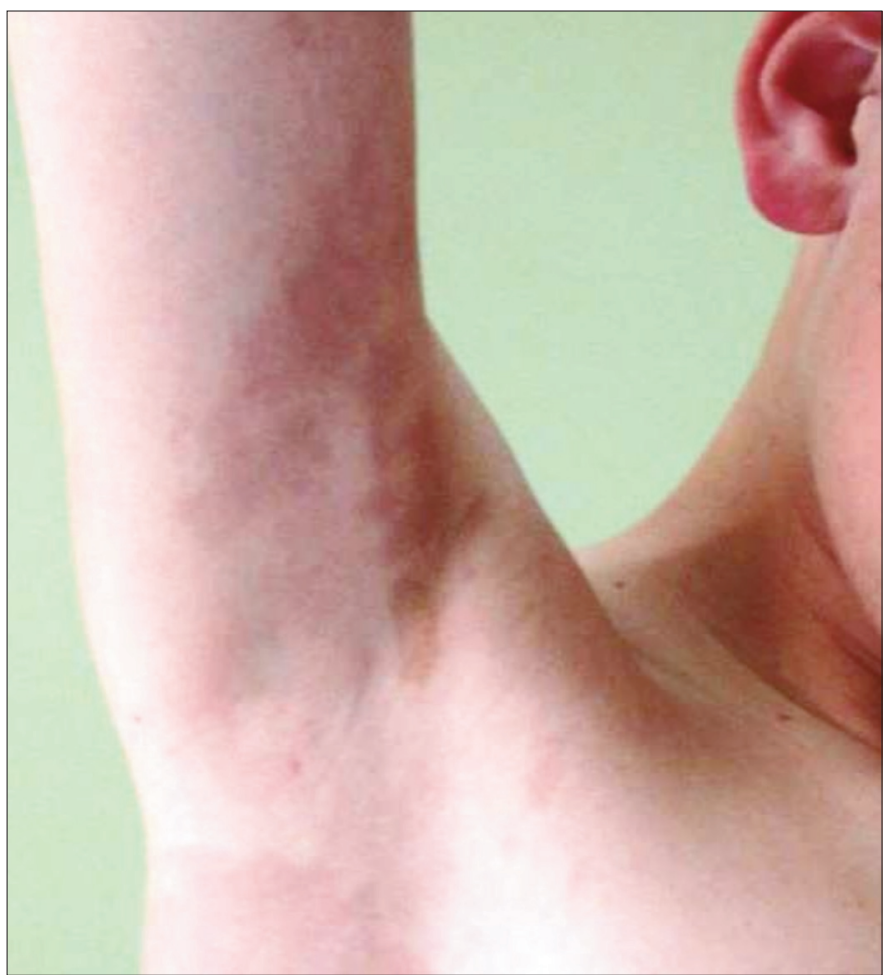

Resim 2. Lineer morfea (Olgu no.13) 
Son 10 yılda lokalize sklerodermadan sistemik skleroza (SS) geçişle ilgili bildirilen olgu raporları ve iç organ tutulumunun izlendiği hasta serileri, lokalize skleroderma ve SS'un birbirinden keskin sınırla ayrılmış 2 ayrı antite değil, bir spektrumun iki ucu olduğu görüşünü uyandırmıştır. Özellikle pediyatrik popülasyonda, sıklıkla SS'daki kadar ciddi ve hayatı tehdit edici olmamakla birlikte başlıca ortopedik, oküler ve nörolojik anormallikler gibi ekstrakutanöz değişikliklerin görülebildiği ve bunun 3. bir ara form olduğu düşünülmektedir., Zulian ve ark. çalışmalarında ${ }^{10} 750$ çocuğun \% 22,4'ünde bir veya daha fazla deri dışı tutulum olduğunu bildirmiştir. Bu hastalardaki 193 ekstrakutanöz bulgunun \%47,2'si artiküler, $\% 17,1$ 'i nörolojik, \%9,3'ü vasküler, \%8,3'ü oküler, \%6,2'si gastrointestinal, \%2,6'sı respiratuvar, \%1'i kardiyak ve \%1'i renal tutulum olarak belirlenmiştir. Nörolojik bulgular arasında epilepsi, santral sinir sistemi vasküliti, periferal nöropati, vasküler malformasyonlar, baş ağrısı ve görüntüleme yöntemleriyle tespit edilen anormallikler bulunmuştur. Oküler bulgular episklerit, üveit, kseroftalmi, glokom ve papilödem olarak gruplanmıştır. On altı hastada Raynaud fenomeni tespit edilirken, akciğer tutulumunun temel olarak restriktif özellikte olduğu görülmüştür. On iki hastada çoğunlukla gastroözefagial reflünün izlendiği gastrointestinal tutulum saptanmıştır. Birden çok sayıda ekstrakutanöz tutulum saptanan 30 hastanın sadece 1'inde sistemik skleroz gelişimi bildirilmiştir. Hasta grubumuzda Zulian ve ark.'nın ${ }^{10}$ grubuyla uyumlu olacak şekilde artiküler tutulum en sık $(\% 47,2)$ ekstrakutanöz tutulum olarak belirlendi. Bunu sırasıyla respiratuvar, nörolojik, gastrointestinal ve oküler tutulum izlemekteydi. Ayrıca 4 hastada livedo retikülaris saptandı.

Marzano ve ark. ${ }^{3} 113$ erişkin, 126 çocuk hasta ile yaptıkları çalışmada lineer morfeanın çocuklarda daha sık olduğunu ve mikst morfeanın daha uzun süreli hastalık ve ciddi seyir ile ilişkili olduğunu göstermiştir. Lineer morfea derin dokuları da tutarak alttaki dokuya fikse olabildiği ve özellikle ilk 2 dekatta görüldüğü için hemiatrofi ve kontraktürlere neden olabilmektedir. ${ }^{11,12}$ Çocukların \%12'sinde ortopedik komplikasyon bulunurken, lineer morfealı çocuklarda bu oranın \%45'e çıktığı görülmüştür. ${ }^{3}$ Çalışma grubumuzda da 3 hastada ortopedik komplikasyon saptandı. Bu hastaların ikisinde lineer morfea, diğer hastada ise lineer komponentin bulunduğu mikst morfea olması, lineer morfealı çocuklarda ortopedik komplikasyonlara daha sık rastlandığı görüşünü desteklemekteydi.

Lineer sklerodermalı hastalarda ekstrakutanöz bulgular diğer klinik tiplere göre daha sık görülür. ${ }^{8}$ En sık görülen ekstrakutanöz bulgular artrit (\%19), nörolojik bulgular (\%4) ve diğer otoimmün hastalıklardır (\%3). Bu hastalarda görülen ekstrakutanöz hastalık genellikle hafif seyirlidir. Çalışmamızda görülen 14 ekstrakutanöz bulgunun 4'ü $(\% 28,6)$ lineer morfealı hastada saptandı.

Zulian ve ark.'nın 750 pediatrik hasta ile yaptıkları çalışmalarında 24 hastada oküler tutulum $(\% 3,2)$ saptanmış, bu hastaların $2 / 3$ 'de ECDS saptanırken $1 / 3$ 'de yüzde lezyon olmaması ilginç bulunmuştur. En sık göz kapakları ve kirpik tutulumu (\%42), anterior üveit, episklerit (\%29) ve daha nadir olarak da paralitik strabismus, psödopapilödem, kırma kusurları izlenmiştir. ${ }^{8}$ Çalışma grubumuzda kol ve bacak tutulumu olan lineer morfealı 1 hastada strabismus saptanırken ECDS'ı olan hastada ise göz tutulumu izlenmedi. ECDS ve Parry Romberg Sendromu'nda hastaların 1/4'de tabloya nörolojik bulguların eşlik ettiği görülmüş, EEG ve SSS görüntülemesinde patolojik bulguların çoğunlukla etkilenen alanla aynı tarafta izlenmesi iki tablonun ilişkili olduğunu düşündürmüştür. ${ }^{13}$ ECDS gelişiminden önce ortaya çıkan epilepsi nöbetlerinin bazen hastalığın ilk bulgusu olabileceği bildirilmiştir. ${ }^{14}$ Ancak bizim çalışmamızda ECDS'ı olan olgumuzda nörolojik tutulum izlenmedi.

On dört morfealı çocuk hasta ile yapılan bir çalışmada özefagial tutulum \%57 gibi oldukça yüksek oranda saptanmıştır. Yazarlar daha geniş hasta serileri ile yapılacak çalışmalarla bu verinin desteklenmesi gerektiğini belirtmiştir. ${ }^{15}$ Hasta grubumuzda 2 hastada disfaji saptandı.

Tüm bu bulgular değerlendirildiğinde, yaygın ve ilerleyici seyir gösteren deri hastalığı olan olgularda, özellikle artralji de tabloya eşlik ediyorsa mevcut semptomlar dikkate alınarak üst gastrointestinal sistem motilite testleri, pulmoner fonksiyon testleri, akciğer grafisi, yüksek çözünürlükte bilgisayarlı tomografi, elektrokardiyogram, ekokardiyografi ve böbrek fonksiyon testlerinden gerekli olanların yapılması önerilmektedir. ${ }^{10}$

Yapılan çalışmalarda morfealı hastalarda çeşitli laboratuvar parametrelerinde değişiklikler gösterilmiştir. ${ }^{16}$ Ekstrakutanöz tutulumu olan hastalarda sedimentasyon (ESR) ve C-reaktif protein (CRP) gibi inflamasyon parametrelerinde daha fazla artış olduğu saptanmıştır. ${ }^{10}$ Yüz yirmi altı çocuk hastada yapılan bir çalışmada hastaların \%2'sinde ESR yüksekliği, \%7'sinde kanda eozinofili izlenmiştir. ANA ve RF pozitifliği artmıştır." ANA pozitifliği hastaların \%26'sında, diğer otoantikorlar ise \%7'sinde tespit edilmiştir. ${ }^{3}$ Hastalarda ANA'nın yanı sıra Scl-70, antisentromer, anti-dsDNA, antihiston ve anti-U1RNP pozitifliği görülebilir. ${ }^{2,18}$ Zulian ve ark. ${ }^{2}$ özellikle derin morfealı hastalarda inflamasyon parametrelerinde yükseklik olduğunu tespit etmiş, ayrıca hastaların $\% 42,3$ 'ünde ANA pozitif saptanmıştır. Artriti olan hastalarda da RF anlamlı derecede yüksek bulunmuştur. ${ }^{2,10}$ Woo ve ark. ${ }^{19}$ ANA ve RF pozitifliğinin ekstrakutanöz tutulum açısından uyarıcı olması gerektiğine dikkat çekmiştir. Hasta grubumuzda inflamasyon parametrelerinde artış saptanmadı. Olgularımızda ANA ve RF pozitifliği olan hastalarda artrit/artralji yoktu. ANA 1/1000 titrede pozitif olan hastada yaygın morfea olması, serolojinin progresyon açısından önemli olabileceğine işaret etmekteydi. RF ve antihiston antikor pozitifliği olan olgularda lineer tutulum olması lineer morfeada otoantikor pozitifliğinin daha sık olduğunu destekler nitelikteydi. Mikst morfeası olan hastada antihiston antikor pozitifliğinin daha uzun süreli ve ciddi hastalık seyrine işaret edebileceği düşünüldü.

\section{Sonuç}

Morfeanın çocukluk çağında en sık görülen formunun lineer morfea olması gelişebilecek kozmetik ve fonksiyonel deformiteler nedeniyle erken tanı ve tedaviyi önemli kılmaktadır. Hastalar ekstrakutanöz semptomlar açısından dikkatle sorgulanmalı ve gerektiğinde ileri tetkikler yapılmalıdır. İnflamasyon parametrelerinde yükseklik, ANA ve RF gibi otoantikor pozitifliğinin ekstrakutanöz tutulum açısından uyarıcı olabileceği unutulmamalıdır.

\section{Kaynaklar}

1. Misra R, Singh G, Aggarwal P, Aggarwak A: Juvenile onset systemic sclerosis: a single center experience of 23 cases from Asia. Clin Rheumatol 2007;26:1259-62.

2. Weber A, Heger S, Sinkgraven R, Heckmann M, Elsner P, Rzany B: Juvenile localized scleroderma: clinical and epidemiological features in 750 children. An international study. Rheumatology 2006;45:614-20.

3. Marzano AV, Menni S, Parodi A, Borghi A, Fuligni A, Fabbri P, et al: Localized scleroderma in adults and children. Clinical and laboratory investigations on 239 cases. Eur J Dermatol 2003;13:171-6.

4. Christen-Zaech S, Hakim MD, Afsar FS, Paller AS: J Am Acad Dermatol 2008;59:385-96

5. Laxer RM, Zulian F: Localized scleroderma. Curr Opin Rheumatol 2006;18:606-13.

6. Herrick AL, Ennis $H$, Bhushan M, Silman AJ, Baildam EM: Incidence of childhood linear scleroderma and systemic sclerosis in the UK and Ireland. Artritis Care \& Research 2010;62:213-8. 
7. Liou JS, Morrell DS: Firm and dyspigmented linear plaques: childhood linear morphea. Pediatric Annals 2007;36:12

8. Zulian F: New developments in localized scleroderma. Curr Opin Rheumatol 2008;20:601-7.

9. Weber K: Is juvenile localized scleroderma related to Lyme borreliozis? I Am Acad Dermatol 2009;61:901

10. Zulian F, Vallongo C, Woo P, Russo R, Ruperto N, Harper J, et al: Localized scleroderma in childhood is not just a skin disease. Arthritis Rheum 2005;52:2873-81.

11. Martini G, Ramanan AV, Falcini F, Girschick H, Goldsmith DP, Zulian F: Successful treatment of severe or methotrexate-resistant juvenile localized scleroderma with mycophenolate mofetil. Rheumatology 2009;48:1410-3.

12. Engin B, Serdaroğlu S: Lokalize sklerodermanın tedavisi. Dermatose 2004;3:140-2.

13. Toffelson MM, Witman DM: En coup de sabre morphea and Parry-Romberg syndrome: a retrospective review of 54 patients. I Am Acad Dermatol 2007:56:257-63.
14. Çerçi Özkan VH, Yalçınkaya C, Tüysüz B, Arısoy N: Epilepsi ile ortaya çıkan bir lineer skleroderma (en coup de sabre) olgusu. Türk Pediatri Arşivi 2003:38:167-70.

15. Guariso G, Conte S, Galeazzi F, Vettorato MG, Martini G, Zulian F: Esophageal involvement in juvenile localized scleroderma: a pilot study. Clin Exp Rheumatol 2007:25.786-89.

16. Kasap B, Soylu A, Türkmen M, Kavukçu S: ỉki olgu nedeniyle juvenil skleroderma. Romatizma 2007;22:151-5.

17. Kawashima H, Watanabe $C$, Kashiwagi $Y$, Sato $S$, loi $H$, Sasamoto $M$, et al. Therapy of childhood generalized morphea: case reports and reviews of the literature of Japanese cases. Pediatrics International 2006;48:342-5.

18. Lehman AM, Patel MS: Childhood-onset hemaiatrophy caused by unilateral morphea. Clinical Dysmorphology 2009;18.213-4.

19. Woo TY, Rasmussen JE: Juvenile linear scleroderma associated with serologic abnormalities. Arch Dermatol 1985;121:1403-5. 